\title{
Mycobacterium parmense sp. nov.
}

Correspondence
Franco Fanti
micromed@unipr.it

In recent years, the role of Mycobacterium scrofulaceum, one of the non-tuberculous mycobacteria, as an aetiological agent of mycobacterial cervical lymphadenitis (scrofula) seems to have declined. An increasing number of cases caused by Mycobacterium avium has been reported, and other cases due to newly identified, scotochromogenic mycobacteria, such as Mycobacterium celatum, Mycobacterium heidelbergense, Mycobacterium interjectum and Mycobacterium tusciae, have been described (Springer et al., 1993; Haase et al., 1994; Wolinsky, 1995; Haas et al., 1997; Howell et al., 1997; Tortoli et al., 1999).

In this study, the isolation of a slow-growing, scotochromogenic mycobacterium from material that was obtained surgically from a cervical lymph node from a 3-year-old girl is reported. The micro-organism proved to be unidentifiable

Published online ahead of print on 16 January 2004 as DOI 10.1099/ ijs.0.02760-0.

The GenBank/EMBL/DDBJ accession number for the $16 \mathrm{~S}$ rDNA sequence of strain MUP $1182^{\top}$ is AF466821.

Supplementary material showing the sequence alignment, fatty acid content and mycolic acid pattern of strain MUP $1182^{\top}$ is available in IJSEM Online. by conventional biochemical tests that are specific for this group. Chromatographic and genetic analyses indicated that the isolate represents a novel species, which is named Mycobacterium parmense sp. nov. because of the place of its first isolation.

Isolate MUP $1182^{\mathrm{T}}$ was recovered from a 3-year-old girl who presented in May 1999 with a local swelling of the left submandibular region that was $\sim 4 \mathrm{~cm}$ in diameter and mildly painful to the touch. While under standard antibiotic therapy, other lymph nodes enlarged and the patient was hospitalized because of her bilateral cervical lymphadenitis. In August 1999, surgical exploration allowed the collection of colliquated material. The specimen was processed in accordance with standard procedures. Microscopic examination revealed the presence of acid-fast bacilli. Tests for Mycobacterium tuberculosis DNA (LCx MTB; Abbott) gave negative results. A slow-growing, scotochromogenic mycobacterium (MUP $1182^{\mathrm{T}}$ ) was recovered by using both conventional and radiometric culture procedures (Kent \& Kubica, 1985; Siddiqi, 1996).

Therapy with a triple regimen that included isoniazid, rifampicin and pyrazinamide, the latter being changed 
subsequently to clarithromycin, was unsuccessful. The mandibular lymph nodes were eventually removed by surgery. No relapses occurred thereafter.

Colony morphology, pigment production in the dark and after photoinduction and ability to grow at $25-45^{\circ} \mathrm{C}$ were determined during 6 weeks incubation on LöwensteinJensen medium. Acid- and alcohol-fastness was determined by Ziehl-Neelsen staining.

Previously described methods were used to determine the standard biochemical reactions of the isolate (Kent \& Kubica, 1985). The following biochemical features were investigated: niacin accumulation, nitrate reductase, arylsulfatase on days 3 and 14, drop-method catalase, semiquantitative catalase, heat-stable catalase $\left(\mathrm{pH} 7,68^{\circ} \mathrm{C}\right)$, tellurite reductase, Tween 80 hydrolysis, $\beta$-glucosidase activity and urease activity. Inhibition tests included tolerance to isoniazid, hydroxylamine, $p$-nitro- $\alpha$-acetylamino- $\beta$ hydroxypropiophenone, $p$-nitrobenzoate, oleate, $5 \%(\mathrm{w} / \mathrm{v})$ $\mathrm{NaCl}$, thiacetazone, thiophene-2-carboxylic acid hydrazide and growth on MacConkey's agar without crystal violet.

The macrodilution method in radiometric broth, recommended for M. avium (Siddiqi et al., 1993), was used to test the susceptibility of the isolate to ciprofloxacin, clofazimine, ethambutol, rifabutin, rifampicin and streptomycin.

The mycolic acids of whole-organism methanolysates were investigated by TLC as described by Minnikin et al. (1984), as well as by HPLC of bromo-phenacyl esters by using a $\mathrm{C}_{18}$ Ultrasphere XL cartridge column (Beckman) on a System Gold instrument (Beckman), according to standard procedures (Butler et al., 1992; Tortoli \& Bartoloni, 1996). Low- and high-molecular-mass internal standards (Ribi; ImmunoChem) were added for peak identification.

Fatty acid methyl esters, alcohols and mycolic acid cleavage products were obtained from $40 \mathrm{mg}$ wet biomass of the isolate, which was saponified, methylated and extracted as described by Miller (1982). They were subsequently separated by GLC using a model 5898A gas chromatograph (Hewlett Packard). Microbial Identification system software (Microbial ID) was used to identify the fatty acids.

DNA was extracted from cells of the isolate by the alkalinewash and heat-lysis method. Briefly, several small colonies were placed into a tube that contained $0.5 \mathrm{ml}$ alkaline wash solution $(0.5 \mathrm{M} \mathrm{NaOH}$ and $0.05 \mathrm{M}$ sodium citrate). Tubes were vortexed and allowed to stand for $5 \mathrm{~min}$ at room temperature. The tubes were then centrifuged at $20800 \mathrm{~g}$ for $5 \mathrm{~min}$ and the supernatant was discarded; $0.5 \mathrm{ml} 0.5 \mathrm{M}$ Tris/ $\mathrm{HCl}, \mathrm{pH} 8 \cdot 0$, was added and the tubes were vortexed again, then centrifuged at $20800 \mathrm{~g}$ for $5 \mathrm{~min}$. The supernatant was discarded, the pellet of cells was suspended in $100 \mu \mathrm{l}$ RNase-free water and the tubes were held at $95^{\circ} \mathrm{C}$ for $15 \mathrm{~min}$ in a heat block.

Amplification and sequencing of the first $500 \mathrm{bp}$ of the $16 \mathrm{~S}$ rRNA gene were carried out with the MicroSeq 500 16S
rDNA Bacterial Sequencing kit (Applied Biosystems). The rest of the gene was sequenced by using the MicroSeq Full Gene 16S rDNA Bacterial Sequencing kit (Applied Biosystems). Sequencing analysis of the 16S rRNA gene was performed by using a MicroSeq sequencing module. Sequencing was performed in an ABI 310016 capillary genetic analyser (Applied Biosystems).

All sequence sample files were assembled and the final sequence was compared with those in a bacterial database containing 1434 entries, including 83 species of mycobacteria (version 1.4.2, February 2002). The Mayo Clinic library of nucleic acid sequences was composed of an additional 24 isolates, including different genotypes of common mycobacterial species (Hall et al., 2003).

The newly determined sequence was aligned with reference $16 \mathrm{~S}$ rDNA sequences from closely related mycobacterial species by using the computer program CLUSTAL $\mathrm{W}$, version 1.81 (Thompson et al., 1994). A phylogenetic tree was constructed by using the neighbour-joining method (Saitou \& Nei, 1987). The method was applied to distances corrected for multiple hits and for unequal transition and transversion rates, according to Kimura's two-parameter model (Kimura, 1980), omitting regions of uncertain alignment at both ends of the gene; tree topology was confirmed by parsimony analysis.

Microscopically, cells of strain MUP $1182^{\mathrm{T}}$ were small, rodshaped, acid- and alcohol-fast and non-motile; no spores or capsules were observed.

The isolate grew slowly ( $>2$ weeks) on Löwenstein-Jensen slants at temperatures ranging from 25 to $37^{\circ} \mathrm{C}$, whereas no growth was seen at 42 or $45^{\circ} \mathrm{C}$. Colonies were small $(\leqslant 1 \mathrm{~mm})$, smooth, raised with round or lobate regular margins and scotochromogenic. Growth was not inhibited by isoniazid, $p$-nitrobenzoate, $p$-nitro- $\alpha$-acetylamino- $\beta$ hydroxypropiophenone or thiophene-2-carboxylic acid hydrazide, but the micro-organism was sensitive to hydroxylamine, oleate, sodium chloride and thiacetazone. No growth was observed on MacConkey's agar without crystal violet.

Strain MUP $1182^{\mathrm{T}}$ possessed urease activity and was able to hydrolyse Tween 80 in $<5$ days. Tests for niacin production, nitrate reduction, tellurite reduction and $\beta$ glucosidase activity were negative. Arylsulfatase activity was negative in the 3-day test and weakly positive after 14 days, catalase activity was rapid by the drop method and was not inactivated by heating to $68^{\circ} \mathrm{C}$, and foam production was $<45 \mathrm{~mm}$ in the semi-quantitative test. Patterns of enzymic activities and metabolic properties demonstrated that the isolate differed from previously described species (Table 1). In particular, isolate MUP $1182^{\mathrm{T}}$ was distinguishable from $M$. tusciae by a negative nitrate reductase test and from Mycobacterium bohemicum by a positive Tween 80 hydrolysis test. MUP $1182^{\mathrm{T}}$ was characterized by a positive Tween 80 hydrolysis test, unlike 
Table 1. Selected distinguishing characteristics of strain MUP $1182^{\top}$ with respect to other slow-growing, scotochromogenic mycobacteria

Species: 1, M. parmense MUP $1182^{\mathrm{T}}$; 2, M. bohemicum; 3, M. flavescens; 4, M. gordonae; 5, M. interjectum; 6, M. lentiflavum; 7, M. scrofulaceum; 8, M. szulgai; 9, M. tusciae; 10, M. xenopi. Reactions are scored as follows:,$-<15 \%$ of isolates positive; + , $>85 \%$ of isolates positive; $\mathrm{V}, 16-85 \%$ of isolates positive; $+/-$, usually absent, or a weak reaction was possible. Blank spaces indicate that the information is not currently available or that the property is unimportant. Data from other taxa were taken from Kent \& Kubica (1985), Reischl et al. (1998), Springer et al. (1993, 1996) and Tortoli et al. (1999).

\begin{tabular}{|c|c|c|c|c|c|c|c|c|c|c|}
\hline Characteristic & 1 & 2 & 3 & 4 & 5 & 6 & 7 & 8 & 9 & 10 \\
\hline Nitrate reduction & - & - & + & - & - & - & - & + & + & - \\
\hline Semi-quantitative catalase activity & - & - & + & + & + & $\mathrm{V}$ & + & + & - & - \\
\hline Tween 80 hydrolysis & + & - & + & + & - & - & - & $\mathrm{V}$ & + & - \\
\hline Arylsulfatase activity (3 days) & - & - & - & - & - & - & - & - & - & $\mathrm{V}$ \\
\hline \multicolumn{11}{|l|}{ Growth at: } \\
\hline $25^{\circ} \mathrm{C}$ & + & + & + & + & - & + & + & + & + & - \\
\hline $45^{\circ} \mathrm{C}$ & - & - & - & - & - & - & - & - & - & + \\
\hline
\end{tabular}

M. lentiflavum, M. scrofulaceum and Mycobacterium xenopi, and by urease activity, unlike Mycobacterium flavescens, Mycobacterium gordonae and M. xenopi.

Strain MUP $1182^{\mathrm{T}}$ proved to be susceptible to all drugs tested, with the exception of isoniazid. MICs $\left(\mu \mathrm{g} \mathrm{ml}^{-1}\right)$ were as follows: ciprofloxacin, $\leqslant 1$; clofazimine, $\leqslant 0 \cdot 12$; ethambutol, $\leqslant 2$; rifabutin, $\leqslant 0 \cdot 12$; rifampicin, $\leqslant 0 \cdot 5$; streptomycin, $\leqslant 2$.

Mycolic acid analysis by TLC showed a pattern that was reminiscent of those of other slow-growing mycobacteria, such as $M$. bohemicum, M. interjectum, M. scrofulaceum, M. tusciae and M. xenopi. Strain MUP $1182^{\mathrm{T}}$ contained $\alpha$-mycolates, ketomycolates and wax esters. Fatty acid analysis revealed a typical mycobacterial pattern that was characterized by the presence of tuberculostearic acid (10methyl $\mathrm{C}_{18: 0}$ ) and saturated and unsaturated elements without side chains. The presence of eicosanol, derived from wax cleavage, was also detected.

Analysis of mycolic acids by HPLC showed a profile that was characterized by two groups of peaks and was not similar in any significant way to that of any mycobacterial species described to date (Fig. 1).

Sequencing of the PCR-amplified $16 \mathrm{~S}$ rDNA of strain MUP $1182^{\mathrm{T}}$ (1533 bp) yielded a unique, as yet undescribed sequence for a mycobacterial species. In contrast to growth behaviour in culture, the sequence pattern was characterized by the occurrence of a short helix 18 within the hypervariable $\mathrm{B}$ region of the $16 \mathrm{~S}$ rRNA gene, which is a molecular signature of fast-growing mycobacteria. These features are shared by a group of micro-organisms that includes M. simiae and other emerging mycobacterial species (Böttger et al., 1993; Kirschner et al., 1993; Meier et al., 1993; Springer et al., 1993, 1996; Floyd et al., 1996,
2000; Haas et al., 1997; Tortoli et al., 1997; Herbst et al., 2001).

Phylogenetic analysis grouped the novel species close to Mycobacterium genavense, $M$. heidelbergense, $M$. interjectum, Mycobacterium kubicae, M. lentiflavum, M. simiae, Mycobacterium triplex and Mycobacterium montefiorense (GenBank accession no. AF330038). In particular, isolate MUP $1182^{\mathrm{T}}$ clusters with M. lentiflavum and M. simiae, with which it shares high $16 \mathrm{~S}$ rDNA sequence similarity (about $98 \%$ ). A phylogenetic tree showing the position of the novel species with respect to closely related mycobacterial species is shown in Fig. 2.

Cervical lymphadenitis (scrofula) represents the most

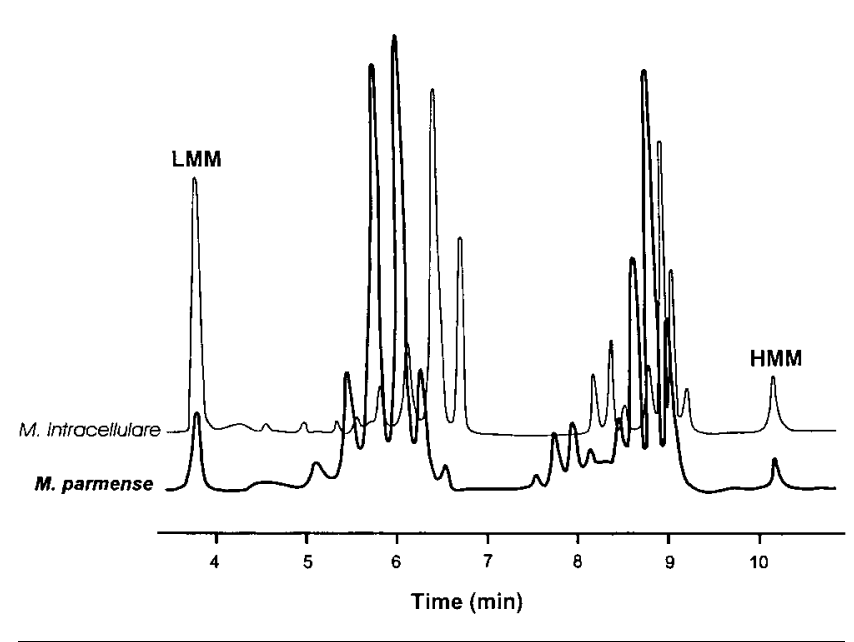

Fig. 1. Mycolic acid pattern of strain MUP $1182^{\top}$, obtained by HPLC analysis, compared with that of Mycobacterium intracellulare. LMM, Low-molecular-mass internal standard; HMM, high-molecular-mass internal standard. 


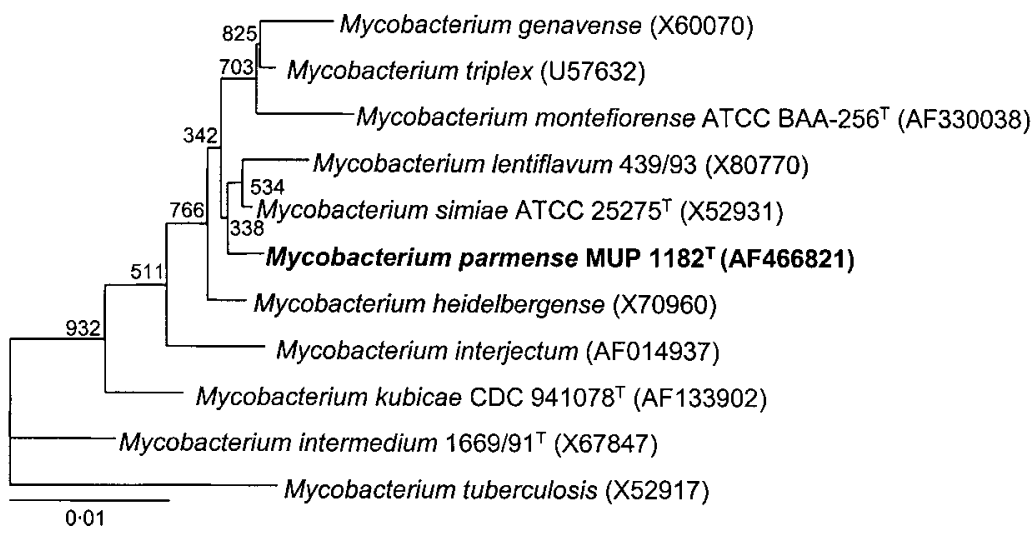

Fig. 2. Phylogenetic tree constructed by using the neighbour-joining method, illustrating the position of $M$. parmense. The sequence of $M$. tuberculosis was used as the outgroup. Bootstrap values for each node are reported. GenBank accession numbers for sequences used to construct the tree are shown in parentheses.

common manifestation of infection with non-tuberculous mycobacteria in childhood. Isolation of a mycobacterial strain from surgically obtained material from a sterile body site strongly suggests a pathogenic role for such micro-organisms (Wallace et al., 1990). Isolate MUP $1182^{\mathrm{T}}$, described in this study, perfectly meets the abovementioned conditions, particularly in view of the fact that microscopy of the clinical specimen revealed acid-fast bacilli.

Strain MUP $1182^{\mathrm{T}}$ was presumptively identified as a $\mathrm{Myco-}$ bacterium species by acid-fastness and morphological and growth characteristics, and its identification was confirmed by lipid analysis and comparative $16 \mathrm{~S}$ rRNA gene sequencing.

Overall, the combined results of nucleic acid analyses, biochemical tests and lipid analysis indicate that the strain described in this study is representative of a novel species in the genus Mycobacterium, for which the name Mycobacterium parmense sp. nov. is proposed.

\section{Description of Mycobacterium parmense sp. nov.}

Mycobacterium parmense (par.men'se. L. neut. adj. parmense pertaining to the Italian city of Parma, where the strain was isolated).

Rod-shaped cells; acid- and alcohol-fast. Growth requires $>2$ weeks at $25-37^{\circ} \mathrm{C}$. No growth occurs at $42^{\circ} \mathrm{C}$. Colonies on Löwenstein-Jensen medium are smooth, raised with round or lobate regular margins and scotochromogenic. The organism produces $<45 \mathrm{~mm}$ foam in the semiquantitative catalase test. Positive for heat-stable catalase, Tween hydrolysis and urease activity. Reactions for nitrate and tellurite reduction, arylsulfatase (3-day test) and $\beta$ glucosidase activities are negative. Growth is inhibited on MacConkey's agar without crystal violet and by addition to the culture medium of $5 \%(\mathrm{w} / \mathrm{v}) \mathrm{NaCl}$, hydroxylamine, thiacetazone or oleate. No inhibition is observed in the presence of $p$-nitrobenzoate, thiophene-2-carboxylic acid hydrazide or $p$-nitro- $\alpha$-acetylamino- $\beta$-hydroxypropiophenone. Susceptible to ciprofloxacin, clofazimine, ethambutol, rifabutin, rifampicin and streptomycin. Resistant to isoniazid.
TLC of mycolic acid methanolysates indicates the presence of $\alpha$-mycolates, ketomycolates and wax esters. The unique HPLC profile is supportive of a novel species. The fatty acid pattern is characterized by hexadecanoic acid $(25 \%)$, hexadecenoic acids (13\%), octadecanoic acid (3\%), octadecenoic acids $(24 \%)$ and tuberculostearic acid $(7 \%)$. Two alcohols, $\mathrm{C}_{18: 0}(8 \%)$ and $\mathrm{C}_{20: 0}(10 \%)$, are also present. Phylogenetic analysis based on the 16S rRNA gene sequence reveals a unique profile; the species was placed in an intermediate position between slow- and fast-growing mycobacteria.

The type strain of $M$. parmense is MUP $1182^{\mathrm{T}}$ (=CIP $107385^{\mathrm{T}}=$ DSM $44553^{\mathrm{T}}$ ).

\section{Acknowledgements}

We are grateful to R. Percudani, University of Parma, Parma, Italy, for his assistance with phylogenetic tree construction.

\section{References}

Böttger, E. C., Hirschel, B. \& Coyle, M. B. (1993). Mycobacterium genavense sp. nov. Int J Syst Bacteriol 43, 841-843.

Butler, W. R., Thibert, L. \& Kilburn, J. O. (1992). Identification of Mycobacterium avium complex strains and some similar species by high-performance liquid chromatography. J Clin Microbiol 30, 2698-2704.

Floyd, M. M., Guthertz, L. S., Silcox, V. A., Duffey, P. S., Jang, Y., Desmond, E. P., Crawford, J. T. \& Butler, W. R. (1996). Characterization of an SAV organism and proposal of Mycobacterium triplex sp. nov. J Clin Microbiol 34, 2963-2967.

Floyd, M. M., Gross, W. M., Bonato, D. A., Silcox, V. A., Smithwick, R. W., Metchock, B., Crawford, J. T. \& Butler, W. R. (2000). Mycobacterium kubicae sp. nov., a slowly growing, scotochromogenic Mycobacterium. Int J Syst Evol Microbiol 50, 1811-1816.

Haas, W. H., Butler, W. R., Kirschner, P. \& 9 other authors (1997). A new agent of mycobacterial lymphadenitis in children: Mycobacterium heidelbergense sp. nov. J Clin Microbiol 35, 3203-3209.

Haase, G., Skopnik, H., Bätge, S. \& Böttger, E. C. (1994). Cervical lymphadenitis caused by Mycobacterium celatum. Lancet 344, 1020-1021.

Hall, L., Doerr, K. A., Wohlfiel, S. L. \& Roberts, G. D. (2003). Evaluation of the MicroSeq system for identification of mycobacteria 
by $16 \mathrm{~S}$ ribosomal DNA sequencing and its integration into a routine clinical mycobacteriology laboratory. J Clin Microbiol 41, 1447-1453.

Herbst, L. H., Costa, S. F., Weiss, L. M., Johnson, L. K., Bartell, J., Davis, R., Walsh, M. \& Levi, M. (2001). Granulomatous skin lesions in moray eels caused by a novel Mycobacterium species related to Mycobacterium triplex. Infect Immun 69, 4639-4646.

Howell, N., Heaton, P. A. \& Neutze, J. (1997). The epidemiology of nontuberculous mycobacterial lymphadenitis affecting New Zealand children 1986-95. N Z Med J 110, 171-173.

Kent, P. T. \& Kubica, G. P. (1985). Public Health Mycobacteriology: a Guide for the Level III Laboratory. Atlanta, GA: US Department of Health and Human Services.

Kimura, M. (1980). A simple method for estimating evolutionary rates of base substitutions through comparative studies of nucleotide sequences. J Mol Evol 16, 111-120.

Kirschner, P., Meier, A. \& Böttger, E. C. (1993). Genotypic identification and detection of mycobacteria - facing novel and uncultured pathogens. In Diagnostic Molecular Microbiology: Principles and Applications, pp. 173-190. Edited by D. H. Persing, T. F. Smith, F. C. Tenover \& T. J. White. Washington, DC: American Society for Microbiology.

Meier, A., Kirschner, P., Schröder, K. H., Wolters, J., Kroppenstedt, R. M. \& Böttger, E. C. (1993). Mycobacterium intermedium sp. nov. Int J Syst Bacteriol 43, 204-209.

Miller, L. T. (1982). Single derivatization method for routine analysis of bacterial whole-cell fatty acid methyl esters, including hydroxy acids. J Clin Microbiol 16, 584-586.

Minnikin, D. E., Minnikin, S. M., Parlett, J. H., Goodfellow, M. \& Magnusson, M. (1984). Mycolic acid patterns of some species of Mycobacterium. Arch Microbiol 139, 225-231.

Reischl, U., Emler, S., Horak, Z., Kaustova, J., Kroppenstedt, R. M., Lehn, N. \& Naumann, L. (1998). Mycobacterium bohemicum sp. nov., a new slow-growing scotochromogenic mycobacterium. Int $J$ Syst Bacteriol 48, 1349-1355.

Saitou, N. \& Nei, M. (1987). The neighbor-joining method: a new method for reconstructing phylogenetic trees. Mol Biol Evol 4, $406-425$.
Siddiqi, S. H. (1996). Bactec 460 TB System: Product and Procedure Manual. Towson, MD: Becton Dickinson.

Siddiqi, S. H., Heifets, L. B., Cynamon, M. H., Hooper, N. M., Laszlo, A., Libonati, J. P., Lindholm-Levy, P. J. \& Pearson, N. (1993). Rapid broth macrodilution method for determination of MICs for Mycobacterium avium isolates. J Clin Microbiol 31, 2332-2338.

Springer, B., Kirschner, P., Rost-Meyer, G., Schröder, K.-H., Kroppenstedt, R. M. \& Böttger, E. C. (1993). Mycobacterium interjectum, a new species isolated from a patient with chronic lymphadenitis. J Clin Microbiol 31, 3083-3089.

Springer, B., Wu, W.-K., Bodmer, T. \& 10 other authors (1996). Isolation and characterization of a unique group of slowly growing mycobacteria: description of Mycobacterium lentiflavum sp. nov. $J$ Clin Microbiol 34, 1100-1107.

Thompson, J. D., Higgins, D. G. \& Gibson, T. J. (1994). ClUSTAL W: improving the sensitivity of progressive multiple sequence alignment through sequence weighting, position-specific gap penalties and weight matrix choice. Nucleic Acids Res 22, 4673-4680.

Tortoli, E. \& Bartoloni, A. (1996). High-performance liquid chromatography and identification of mycobacteria. Rev Med Microbiol 7, 207-219.

Tortoli, E., Piersimoni, C., Kirschner, P. \& 10 other authors (1997). Characterization of mycobacterial isolates phylogenetically similar to, but different from, Mycobacterium simiae. J Clin Microbiol 35, 697-702.

Tortoli, E., Kroppenstedt, R. M., Bartoloni, A., Caroli, G., Jan, I., Pawlowski, J. \& Emler, S. (1999). Mycobacterium tusciae sp. nov. Int J Syst Bacteriol 49, 1839-1844.

Wallace, R. J., Jr, O’Brien, R., Glassroth, J., Raleigh, J. \& Dutt, A. (1990). Diagnosis and treatment of disease caused by nontuberculous mycobacteria. Statement of the American Thoracic Society, prepared by an ad hoc committee of the Scientific Assembly on Microbiology, Tuberculosis, and Pulmonary Infections. Am Rev Respir Dis 142, 940-953.

Wolinsky, E. (1995). Mycobacterial lymphadenitis in children: a prospective study of 105 nontuberculous cases with long-term follow-up. Clin Infect Dis 20, 954-963. 